\title{
Transposon Mutagenesis of Xylella fastidiosa by Electroporation of Tn5 Synaptic Complexes
}

\author{
Magalie R. Guilhabert, ${ }^{1}$ Les M. Hoffman, ${ }^{2}$ David A. Mills, ${ }^{3}$ and Bruce C. Kirkpatrick ${ }^{1}$ \\ ${ }^{1}$ Department of Plant Pathology, University of California-Davis, 1 Shields Avenue, Davis 95616, U.S.A.; \\ ${ }^{2}$ Epicentre Technologies, 1202 Ann Street, Madison 53713, WI, U.S.A; ${ }^{3}$ Department of Viticulture and \\ Enology, University of California-Davis, 1 Shields Avenue, Davis 95616, U.S.A. \\ Submitted 7 December 2000; Accepted 2 March 2001.
}

Pierce's disease, a lethal disease of grapevine, is caused by Xylella fastidiosa, a gram-negative, xylem-limited bacterium that is transmitted from plant to plant by xylemfeeding insects. Strains of $X$. fastidiosa also have been associated with diseases that cause tremendous losses in many other economically important plants, including citrus. Although the complete genome sequence of $X$. fastidiosa has recently been determined, the inability to transform or produce transposon mutants of $X$. fastidiosa has been a major impediment to understanding pathogen-, plant-, and insect-vector interactions. We evaluated the ability of four different suicide vectors carrying either Tn5 or Tn10 transposons as well as a preformed Tn5 transposase-transposon synaptic complex (transposome) to transpose $X$. fastidiosa. The four suicide vectors failed to produce any detectable transposition events. Electroporation of transposomes, however, yielded $6 \times 10^{3}$ and $4 \times 10^{3} \mathrm{Tn} 5$ mutants per $\mu \mathrm{g}$ of DNA in two different grapevine strains of $X$. fastidiosa. Molecular analysis showed that the transposition insertions were single, independent, stable events. Sequence analysis of the Tn5 insertion sites indicated that the transpositions occur randomly in the $X$. fastidiosa genome. Transposome-mediated mutagenesis should facilitate the identification of $X$. fastidios $a$ genes that mediate plant pathogenicity and insect transmission.

Pierce's disease (PD), a lethal disease of grapevine, is caused by Xylella fastidiosa, a gram-negative, xylem-limited bacterium (Davis et al. 1978; Goheen et al. 1973; Hopkins et al. 1973) that is transmitted from plant to plant by several kinds of xylem sap-feeding insects (Frazier 1965). Vines develop symptoms when the bacteria multiply and block the xylem elements, reducing the flow of water to affected leaves. All varieties of Vitis vinifera grapevines die following infection. Historically, major epidemics have occurred in several grape-growing regions of California. A recent epidemic in northern California resulted in $\$ 33$ million in losses from 1995 to 1998. A recent outbreak of PD in southern California's Temecula Valley, caused by the introduction of a new $X$. fastidiosa insect vector, the glassy winged sharpshooter

Corresponding author: B. Kirkpatrick;

E-mail: bckirkpatrick@ucdavis.edu
(Homalodisca coagulata), has caused over \$6 million in damage since 1997. Strains of $X$. fastidiosa also have been associated with diseases that cause losses in many other economically important plants, including peach, plum, oleander, elm, sycamore, oak, maple, citrus, and coffee (De Lima et al. 1998; Purcell 1997).

Understanding the complex interactions among the plant, pathogen, and insect vector is imperative for the development of effective disease controls. Recently, the complete genome sequence of a citrus strain of $X$. fastidiosa (Simpson et al. 2000) was determined. Analysis of its genome revealed important information on potential plant pathogenicity and insect transmission genes. More than half (53\%) of the identified open reading frames (ORFs) in $X$. fastidiosa encode proteins with no assignable function (Simpson et al. 2000). In addition, some of the putative gene functions assigned on the basis of sequence homology with other prokaryotes may be incorrect. In order to identify and understand the function of $X$. fastidiosa genes, it is imperative to develop techniques to knock out and complement putative pathogenicity or transmission genes. Despite numerous attempts, no systems have been developed to genetically manipulate $X$. fastidios $a$.

Transposable elements have become valuable mutagenic tools for genetic and molecular analysis in many different bacteria (Voelker and Dybvig 1998). The most widely used transposon in gram-negative bacteria is Tn5 (Bruijn and Lupski 1984), which transposes at high frequency, has relatively little target-sequence specificity (Goryshin et al. 1998), and does not share homology with genomic sequences of most bacterial species (Berg and Berg 1983). Transposon mutagenesis, however, can have the following technical limitations: i) the transposase gene must be expressed in the target host; ii) the transposon must be introduced into the host on a suicide vector; and iii) the transposase gene on the transposon can be expressed in subsequent generations, which may result in genetic instability. To overcome the above problems, Goryshin et al. (2000) developed the "transposome" system. The transposome is an association between a hyperactive Tn5 transposase and a linearized $\operatorname{Tn} 5$ minitransposon that contains a selectable marker flanked at each end by modified 19-bp transposase recognition sequences of Tn5 (Goryshin and Reznikoff 1998). In the absence of magnesium ions, the DNA-protein complex is stable and may be electroporated into bacterial cells and the Tn5 element can subsequently un- 
dergo transposition in vivo (Goryshin et al. 2000). Because the transposase is degraded in the cell, no subsequent transposition occurs. In this paper, we describe the successful use of a transposome to mutagenize $X$. fastidiosa. To our knowledge, this is the first report of a transposition system for $X$. fastidiosa and the first use of a transposome to mutate a plant-pathogenic bacterium.

\section{RESULTS}

Electroporations with the two suicide vectors pBSL181 and pBSL346 failed to give any antibiotic-resistant colonies. Following electroporation with suicide plasmids p2021 and pSUP102Cm::Tn5, numerous small colonies initially grew on antibiotic supplemented PD3 agar plates. Upon transfer, however, these microcolonies did not grow in liquid PD3 medium supplemented with $5 \mu \mathrm{g}$ of kanamycin per ml.

In contrast, when the transposase-Tn 5 DNA synaptic complexes were electroporated into the Fetzer strain of $X$. fastidiosa, $115 \mathrm{Kan}^{\mathrm{R}}$ colonies were obtained in the first experiment. Eighty individual colonies were transferred into 3 and $35 \mathrm{ml}$ of liquid PD3 medium supplemented with $5 \mu \mathrm{g}$ of kanamycin per ml. Seven cultures became contaminated, and DNA isolated from the remaining $73 \mathrm{Kan}^{\mathrm{R}}$ clones was analyzed by dot blot hybridization with Tn5 as a probe. Sixty-seven of these colonies possessed Tn5 DNA (data not shown). Two of the six Kan ${ }^{\mathrm{R}}$ colonies that tested negative by dot blot hybridization were sequenced. These colonies contained Tn5 insertions (Table 1), suggesting that the other four dot blot-negative $\mathrm{Kan}^{\mathrm{R}}$ clones probably contained Tn5. Controls in which no transposome complex was added failed to yield any $\operatorname{Kan}^{\mathrm{R}}$ colonies on selective PD3 agar plates, indicating no spontaneous production of kanamycin-resistant colonies. No $\mathrm{Kan}^{\mathrm{R}}$ colonies were obtained when the cells were electroporated only with transposon DNA, indicating that the transposition event is transposase dependant. Southern blot analysis of $10 \mathrm{Kan}^{\mathrm{R}}$ colonies showed that eight of the $\mathrm{Kan}^{\mathrm{R}}$ colonies tested contained a single transposon insertion, and one clone may contain two Tn5 insertions (Fig. 1, lane 10). DNA from one clone did not hybridize initially to the Tn5 DNA probe (Fig. 1, lane 6). Southern analysis of a second restriction digest, however, did yield positive hybridization results (data not shown).

The transposon boundaries of the $10 \mathrm{Kan}^{\mathrm{R}}$ Fetzer clones were sequenced in order to localize the inserts in the $X$. fastidiosa genome (Table 1). DNA from these X. fastidiosa $\operatorname{Tn} 5$ mutants was cloned into cosmids in Escherichia coli. One to five kanamycin-resistant colonies were observed on kanamycin-plus-chloramphenicol plates for each cosmid "rescue" attempt of $X$. fastidiosa DNA from the $10 \mathrm{Kan}^{\mathrm{R}}$ clones. Sequence analysis indicated that nine inserts generated 9-bp duplication at the boundaries, which is expected for a Tn5transposase-mediated transposition (Goryshin and Reznikoff 1998). One product, FD7, showed an exceptional insertion of 10-bp duplications at the boundaries (Table 1), which has been observed with in vitro insertion of Tn5 transposomes (I. Goryshin, personal communication), but not with in vivo Tn5 transpositions. The sequences of $X$. fastidiosa DNA flanking the insertion sites were subjected to a BLAST homology search against the genome sequence of the citrus strain of $X$. fastidiosa. Two Tn5 insertions are in intergenic regions and eight are in recognized or hypothetical ORFs (Table 1).

In order to assess the stability of the X. fastidiosa Tn5 mutants, 72 mutants were grown for two passages, once in nonselective liquid and once on nonselective solid PD3 medium. After the two transfers, 70 of the mutants subsequently grew on PD3 agar plates supplemented with $5 \mu \mathrm{g}$ of kanamycin per $\mathrm{ml}$. For unknown reasons, two of the 72 putatively transposed clones did not grow in the first passage in nonselective, liquid PD3 medium.

Because a transformation system can be highly strain dependant, transposome electroporation experiments were performed with a second $X$. fastidiosa strain, termed "Temecula." Following electroporation, $74 \mathrm{Kan}^{\mathrm{R}}$ Temecula strain colonies grew on PD3 medium supplemented with $5 \mu \mathrm{g}$ of kanamycin per $\mathrm{ml}$, indicating that the Temecula, like the Fetzer $X$. fastidiosa strain, is amenable to transposition with the transposome system. To date, we have generated over 1,000 Tn5 mutants of the Temecula strain. This discovery is particularly important because the genome sequence of the grape-derived Temecula strain is now being determined in Brazil.

Table 1. Sequence analysis and putative function of Xylella fastidiosa DNA flanking Tn 5 transposon insertions in the Fetzer grapevine strain

\begin{tabular}{|c|c|c|c|c|}
\hline $\begin{array}{l}\text { Tn5 } \\
\text { clone }\end{array}$ & Sequence of $X$. fastidiosa DNA flanking Tn $5^{a}$ & $\begin{array}{l}\text { Open reading } \\
\text { frame (ORF) } \\
\text { designation }^{b}\end{array}$ & $\begin{array}{l}\text { Map location of } X . \text { fas- } \\
\text { tidiosa citrus variegated } \\
\text { chlorosis (CVC) strain }\end{array}$ & $\begin{array}{l}\text { Putative gene } \\
\text { function }^{d}\end{array}$ \\
\hline FB1 & gtttatggctcaCACCGTGGC $<$ KanR $>$ CACCGTGGCtgctgtggcccc & Xf2752 & $(2,643,701-2,643,709)$ & Unknown ${ }^{\mathrm{e}}$ \\
\hline FB2 & ggacatcacacaGCATGAAGG $<$ KanR $>$ GCATGAAGGtatcggcagatt & & $(943,970-943,978)$ & Intergenic insertion \\
\hline FB3 & tgcggetgtattGCTATCACA $<$ KanR $>$ GCTATCACAttaatacagcag & Xf1854 & $(1,770,398-1,770,406)$ & Unknown \\
\hline FB9 & ttccttctagcaGGTTTTTTG $<$ KanR $>$ GGTTTTTTGgtttcccatcag & Xf0070 & $(64,213-64,371)$ & Unknown \\
\hline FC2 & ttgttccagtgaCTGCAACAC $<$ KanR $>$ CTGCAACACcgtaggcactcg & Xf1903 & $(1,810,187-1,810,195)$ & $\begin{array}{l}\text { Potassium transport } \\
\text { protein }\end{array}$ \\
\hline FD5 & ggtttgaagcaGCATTGTGT $<$ KanR $>$ GCATTGTGTtccgccagaagt & Xf1056 & $(1,015,537-1,015,545)$ & Unknown \\
\hline FD6 & tgcttcaaaaccGTACTAACA $<$ KanR $>$ GTACTAACAgttgctttaaag & Xf1919 & $(1,824,956-1,824,964)$ & $\begin{array}{l}\text { Similar to human } \mathrm{K}+ \\
\text { channel protein }\end{array}$ \\
\hline FD7 & agagcattggcaGTACATGAAC $<$ KanR $>$ GTACATGAACcgatccgccett & Xf0156 & $(159,967-159,976)$ & $\begin{array}{l}\text { Putative cysteine } \\
\text { protease }\end{array}$ \\
\hline FD10 & ttgactggatctGTCATAAAC $<$ KanR $>$ GTCATAAACacaacetgccat & & $(1,895,553-1,895,561)$ & Intergenic insertion \\
\hline FE1 & agtaaactctgaGGTGAGGAT $<$ KanR $>$ GGTGAGGATtcgctatttata & Xf2677 & $(2,551,921-2,551,929)$ & L-ascorbate oxidase \\
\hline
\end{tabular}

${ }^{a}$ Bases in capital letters indicate duplicated $\operatorname{Tn} 5$ insertion site.

${ }^{\mathrm{b}}$ Identification number of ORF in CVC strain of X. fastidiosa (Simpson et al. 2000).

${ }^{\mathrm{c}}$ Numbers indicate the position of the Tn 5 transposon in the genomic sequence of the CVC strain of X. fastidiosa (Simpson et al. 2000).

${ }^{d}$ Putative function of ORF on the basis of homology with other gene sequences.

${ }^{\mathrm{e}}$ Function of ORF is unknown. 


\section{DISCUSSION}

We demonstrated that a simple mutagenesis system that is based on a transposon-transposase synaptic complex (transposome) can produce $\mathrm{Tn} 5$ transposon mutants of $X$. fastidiosa. The transposome DNA is an association between a transposase and a transposon containing only the kanamycin resistance gene of Tn903 (Oka et al. 1981) flanked at each end by the 19-bp transposase recognition sequence of $\operatorname{Tn} 5$ (Goryshin et al. 1998). As previously discussed, this transposition system has several desirable features that make it suitable for mutagenizing $X$. fastidiosa. As previously demonstrated in other prokaryotes (Gehring et al. 2000; Goryshin et al. 2000) and Southern blot and sequence analyses of $10 \mathrm{X}$. fastidiosa transposition mutants, these transpositions occur at random sites on the $X$. fastidiosa chromosome. Tn5 transposons inserted in both orientations with respect to $X$. fastidiosa ORFs, which indicates that transcription of the kanamycin resistance gene is under control of the Tn903 promoter and not a $X$. fastidiosa promoter.

Because the mini transposon used in this study lacks the transposase gene, it can no longer transpose once inserted in the chromosome, which results in genetically stable Tn5 mutants. This stability was demonstrated when 70 of the transposed products did not lose their kanamycin resistance when grown on medium lacking antibiotic.

No $\mathrm{Kan}^{\mathrm{R}}$ colonies were obtained when $X$. fastidiosa cells were electroporated with four suicide vectors: pBSL181, pBSL346, pSUP102Cm::Tn5, and pSUP2021. One explanation for these results might be the lack of expression of the transposase genes in a $X$. fastidiosa background. Alternatively, the antibiotic promoters on these suicide vectors, which were different from the promoter driving expression of the transposome-kanamycin resistance gene, may not be functional in $X$. fastidiosa. Another explanation might be that the transformation efficiency of these four suicide vectors may not have been high enough, compared with the transposome, to detect a transposition event.

The transposition efficiency was approximately $6 \times 10^{3}$ and $4 \times 10^{3} \operatorname{Tn} 5$ mutants per $\mu \mathrm{g}$ of transposome DNA for the Fetzer and Temecula strains, respectively. The electrical parameters we used generally yielded 2 to $5 \%$ survival of electroporated cells. In two additional preliminary electroporation experiments, the survival rate was below $1 \%$ and no transposition products were obtained. Thus, the number of $\operatorname{Tn} 5$ mutants obtained is highly dependent upon optimizing transformation efficiency. Because no transformation system with plasmid DNA has been available for grapevine strains of $X$. fastidiosa, the transposome mutagenesis system should facilitate the experimental determination of optimal electroporation conditions for $X$. fastidiosa.

The transposome approach should allow the identification of $X$. fastidiosa genes that mediate plant pathogenicity and insect transmission. Detailed analysis of the citrus strain of $X$. fastidiosa assigned putative function to approximately half of the $X$. fastidiosa ORFs. Random Tn5 mutagenesis will allow large numbers of genes to be screened for function, without performing gene knockout experiments on ORFs with unknown function. Our $X$. fastidiosa transposition mutants are currently being inoculated into grapevines in order to identify genes that allow $X$. fastidiosa cells to colonize, move, and cause disease in grapevines. Hopefully, mutagenesis studies, in conjunction with the additional genome sequence of the Temecula grapevine strain of $X$. fastidiosa, will lead to a bet-

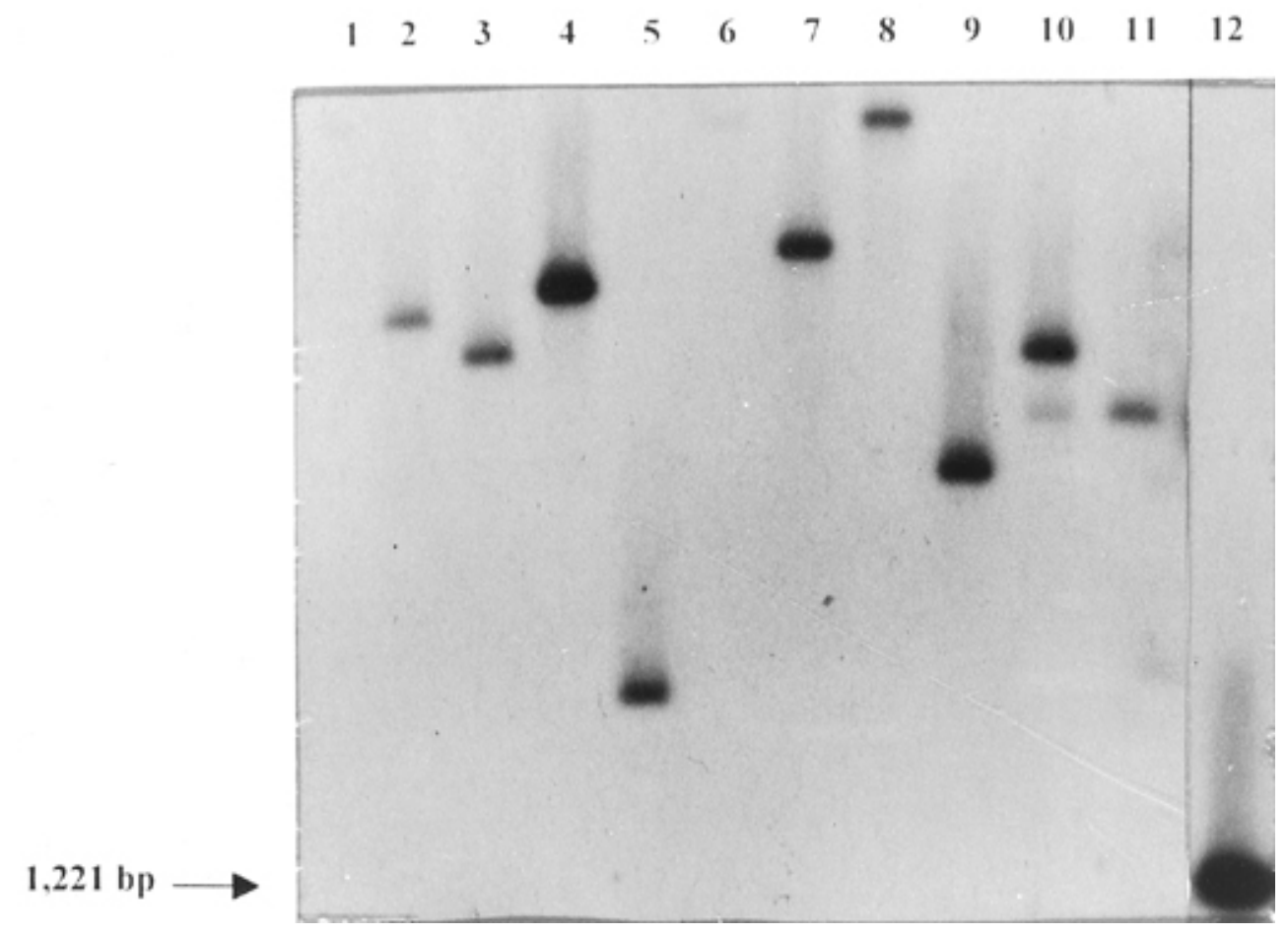

Fig. 1. Southern blot analysis of transposition clones of Xylella fastidiosa. Lane 12: $10 \mathrm{ng}$ of Tn5 positive control DNA (1,221 bp). Lane 1: EcoRI-EagIdigested DNA isolated from $X$. fastidiosa cells that were not electroporated with Tn 5 transposome. Lanes 2-11, Individual Tn 5 transposition clones of $X$. fastidiosa. Approximately $600 \mathrm{ng}$ of $X$. fastidiosa genomic DNA were digested by EcoRI-EagI restriction enzymes. 
ter understanding of the molecular mechanisms of X. fastidiosa pathogenicity and, perhaps, suggest novel treatments for PD.

\section{MATERIALS AND METHODS}

\section{Bacterial strains and constructs used in this study.}

The $X$. fastidiosa strains Fetzer (Hendson et al. 2001) and Temecula (this study) were isolated from symptomatic, PDaffected grapevines in Napa Valley and Temecula Valley, in California. Following isolation, the strains were grown in liquid PD3 medium (Davis et al. 1981), 15\% of glycerol was added, and the cells were stored at $-80^{\circ} \mathrm{C}$.

Two suicide vectors carrying the transposon Tn5, pSUP102Cm::Tn5 $\left(\mathrm{Tc}^{\mathrm{R}}\right)$ (Simon et al. 1988), and pSUP2021 $\left(\mathrm{Nm}^{\mathrm{R}}\right)$ (Simon et al. 1983), and two suicide-vectors carrying the transposon Tn10, pBSL181 $\left(\mathrm{Cm}^{\mathrm{R}}\right)$, and pBSL346 $\left(\mathrm{Tc}^{\mathrm{R}}\right)$ (Alexeyev and Shokolenko 1995) were evaluated for their ability to transpose $X$. fastidiosa cells. Plasmid DNAs were purified with a midi-prep kit (Qiagen, Valencia, CA, U.S.A.), according to the manufacturer's recommendations. Preformed Tn5 transposase-transposon complex (transposome) (Goryshin et al. 2000) EZ::TN <Kan-2> Tnp was supplied by the manufacturer (Epicentre Technologies, Madison, WI, U.S.A.).

\section{Preparation of electrocompetent $X$. fastidiosa cells.}

Because $X$. fastidiosa cells stored at $-80^{\circ} \mathrm{C}$ grow poorly when seeded directly into liquid culture, the cells were initially plated on PD3 agar plates. After incubating for 10 to 12 days at $28^{\circ} \mathrm{C}$, a piece of agar medium containing $X$. fastidiosa cells was cut from a plate and used to inoculate $35 \mathrm{ml}$ of liquid PD3 medium. These liquid cultures were allowed to grow for 7 to 10 days at $28^{\circ} \mathrm{C}$; then the cell density was adjusted to $10^{6}$ cells per $\mathrm{ml}$ (optical density at $600 \mathrm{~nm}$ of 0.0025 ) with fresh PD3 medium. Adjusted cell culture $(100 \mu \mathrm{l})$ was used to inoculate each of six PD3 agar plates. After 6 days at $28^{\circ} \mathrm{C}$, the cells were gently washed off each plate with 2 to $3 \mathrm{ml}$ of PD3 medium. The cells were harvested by centrifugation $(5,000 \mathrm{~g})$ at $4^{\circ} \mathrm{C}$ for $5 \mathrm{~min}$, washed in $10 \mathrm{ml}$ of cold, sterile $10 \%$ glycerol, concentrated by centrifugation, and suspended in $1 \mathrm{ml}$ of cold $10 \%$ glycerol. The suspension was centrifuged at $5,000 \mathrm{~g}$ for $5 \mathrm{~min}$ at $4^{\circ} \mathrm{C}$, resuspended in $10 \%$ glycerol to a final concentration of approximately $10^{9}$ cells per $\mathrm{ml}$, and held on ice until electroporated with the transposon constructs.

\section{$X$. fastidiosa electroporation protocol.}

Aliquots $(20 \mu \mathrm{l})$ of concentrated, electrocompetent cells were transferred to a cold, $1.5-\mathrm{ml}$ microcentrifuge tube containing $20 \mathrm{ng}$ of transposome DNA or $100 \mathrm{ng}$ of plasmid DNA. The cell-DNA mixture was placed between the chilled electrodes of an electroporation chamber $(0.15-\mathrm{cm}$ gap; GIBCO-BRL, Grand Island, NY, U.S.A.) and subjected to a single, high-voltage pulse. Pulses were generated and delivered with the Cell-Porator electroporation system (GIBCOBRL). An electric field of $10 \mathrm{kV}$ per $\mathrm{cm}$ for $5 \mathrm{msec}$, with a resistance value of $4 \mathrm{k} \Omega$ and a capacitance of $330 \mu \mathrm{F}$, was applied across the cell-DNA suspension. After the pulse delivery, the cells were immediately removed from the electroporation chamber and inoculated into $1 \mathrm{ml}$ of liquid PD3 medium without antibiotics. The cells were incubated for $24 \mathrm{~h}$ at $28^{\circ} \mathrm{C}$ with constant shaking (100 rpm) to allow expression of antibiotic resistance. After incubation, the putative transformants were selected on PD3 agar plates containing, per ml, $5 \mu \mathrm{g}$ of kanamycin, $10 \mu \mathrm{g}$ of tetracycline, or $5 \mu \mathrm{g}$ of chloramphenicol, depending upon the antibiotic marker of the construct. The $1 \mathrm{ml}$ of liquid PD3 medium containing the electroporated sample was plated entirely on 10 plates of selective PD3 medium.

The presumed transposed cells were chosen on the basis of colony morphology and growth rate, which is typical for $X$. fastidiosa. Transposition efficiency was calculated as the number of Tn5 transformants per microgram of transposome DNA. One control consisted of an aliquot of concentrated cells, which was not electroporated. A second control consisted of electroporating a $20-\mu \mathrm{l}$ aliquot of concentrated cells that was mixed with $20 \mathrm{ng}$ of transposon DNA without the addition of purified transposase protein. The colony-forming units per milliliter of the cell suspension was determined by serial-dilution plating on nonselective PD3 agar plates. To assess cell survival following electroporation, $20 \mu \mathrm{l}$ of $X$. fastidiosa cells, not mixed with DNA, were electroporated. After pulse delivery, the electroporated $X$. fastidiosa cells were diluted in $1 \mathrm{ml}$ of PD3 medium, without antibiotics. For serial dilution plating on nonselective PD3 agar plates, $100 \mu \mathrm{l}$ of PD3 medium was used. The remaining portion of the culture was incubated for $24 \mathrm{~h}$ at $28^{\circ} \mathrm{C}$ and plated on selective PD3 medium supplemented with antibiotics to assess the possible production of spontaneous, antibiotic-resistant colonies.

\section{Isolation of genomic DNA \\ from $X$. fastidiosa Tn5 transformants.}

Antibiotic-supplemented PD3 medium $(3 \mathrm{ml})$ was inoculated with cells from a putative Tn5 transformant and incubated with shaking for 7 to 10 days at $28^{\circ} \mathrm{C}$. The cultures that grew were transferred into $35 \mathrm{ml}$ of liquid PD3 medium supplemented with $5 \mu \mathrm{g}$ of kanamycin per ml. After incubating for 7 to 10 days at $28^{\circ} \mathrm{C}, X$. fastidiosa genomic DNAs were isolated from the transformants with a hexadecyltrimethylammonium bromide-sodium dodecyl sulfate (SDS) procedure (Wilson et al. 1987).

\section{Dot blot and Southern blot analyses of putative $X$. fastidiosa Tn5 mutants.}

Linearized pMOB-2 <Kan-2> (Epicentre Technologies) transposon vector DNA containing a kanamycin resistance gene flanked at each end by 19-bp transposase-recognition sequences was polymerase chain reaction (PCR) amplified with primers complementary to the $19-\mathrm{bp}$ end sequences $\left(5^{\prime}-\right.$ AGATGTGTATAAGAGACAG-3'). PCR was performed with 1× PCR buffer (Perkin-Elmer, Branchburg, N.J., U.S.A.); 1 ng of template DNA; $1 \mu \mathrm{M}$ primers; $0.15 \mu \mathrm{M}$ dATP, dCTP, dGTP, dTTP; and $1 \mathrm{U}$ of AmpliTaq DNA polymerase (Perkin-Elmer) in a final volume of $30 \mu \mathrm{l}$. The amplification was performed according to the manufacturer's recommendations (Epicentre Technologies). The PCR product was gel purified with the QIAquick PCR purification kit (Qiagen). Approximately 100 ng of purified Tn5 DNA was ${ }^{32} \mathrm{P}$-labeled with random primers (Feinberg and Vogelstein 1983). The ${ }^{32} \mathrm{P}$-labeled Tn5 DNA was used as a probe in Southern and dot blot hybridization analyses of restriction-digested or undigested genomic DNAs from $X$. fastidiosa Tn5 mutants growing in PD3 liquid me- 
dium containing kanamycin. Approximately $600 \mathrm{ng}$ of genomic DNA from 10 randomly selected transposed $X$. fastidiosa colonies were digested overnight with EcoRI and EagI restriction enzymes (New England Biolabs, Beverly, MA, U.S.A.), according to the manufacturer's recommendations. EcoRI-EagI-digested genomic DNAs were electrophoresed, alkali-denatured, and transferred to a nitrocellulose membrane (Maniatis et al. 1984). Prehybridizations and hybridizations were carried out in modified Church buffer (Church and Gilbert 1984). Stringent posthybridization wash conditions (30 min per wash) were performed twice in $2 \times$ SSC ( $1 \times$ SSC is $0.15 \mathrm{M} \mathrm{NaCl}$ plus $0.015 \mathrm{M}$ sodium citrate) $-0.1 \% \mathrm{SDS}$ at room temperature and twice in $0.1 \times \mathrm{SSC}-0.1 \% \mathrm{SDS}$ at $68^{\circ} \mathrm{C}$.

\section{Cosmid cloning of Tn5-tagged regions of $X$. fastidiosa DNA.}

The pWEB::TNC Cosmid Cloning Kit (Epicentre) was used for end repair, ligation, packaging, and plating of cosmid libraries obtained from approximately $100 \mathrm{ng}$ of $X$. fastidiosa genomic DNA isolated from $10 \mathrm{Tn} 5 X$. fastidiosa mutants. $X$. fastidiosa genomic DNAs were blunt-end repaired and ligated to $0.5 \mu \mathrm{l}$ of pWEB::TNC blunt, dephosphorylated cosmid vector, according to the manufacturer's protocol. The ligation mixture was precipitated with 2 vol of ethanol and suspended in $10 \mu \mathrm{l}$ of sterile deionized water.

MaxPlax Lambda packaging extract ( $25 \mu \mathrm{l}$; Epicentre) were added to each ligation mixture and further processed, according to the manufacturer's protocol. The phage mixture was added to $1 \mathrm{ml}$ of late-log-phase E. coli $\mathrm{DH} 10 \mathrm{~B}$, incubated at room temperature for $20 \mathrm{~min}$, centrifuged briefly, and resuspended in $350 \mu \mathrm{l}$ of Luria-Bertani (LB) broth. The cells $(100 \mu \mathrm{l})$ were spread on LB plates containing $25 \mu \mathrm{g}$ of chloramphenicol per $\mathrm{ml}$ or $25 \mu \mathrm{g}$ of chloramphenicol and $25 \mu \mathrm{g}$ of kanamycin per ml. Plates were incubated at $37^{\circ} \mathrm{C}$ overnight.

\section{Sequence analysis}

\section{of cosmids containing $X$. fastidiosa Tn 5 DNA.}

Cosmid DNA was purified from 5 to $10 \mathrm{ml}$ of overnight $E$. coli cultures, which grew in LB broth containing $25 \mu \mathrm{g}$ of kanamycin per ml, with the Wizard Plus SV Kit (Promega, Madison, WI, U.S.A.). Five hundred nanograms of cosmid DNA was used as template in " $2 X$ " Big Dye Terminator sequencing reactions (Applied Biosystems, Foster City, CA, U.S.A.), according to the manufacturer's protocols. Samples were cycled in a DNA Engine (MJ Research, Waltham, MA, U.S.A.) for $4 \mathrm{~min}$ at $95^{\circ} \mathrm{C}$, then 55 to 60 cycles of $30 \mathrm{~s}$ at $95^{\circ} \mathrm{C}, 5 \mathrm{~s}$ at $55^{\circ} \mathrm{C}$, and $4 \mathrm{~min}$ at $60^{\circ} \mathrm{C}$. Sequencing reactions were purified with a Centri-Sep spin column (Princeton Separations, Princeton, NJ, U.S.A.), concentrated by ethanol precipitation, and resuspended in $20 \mu \mathrm{l}$ of Template Suppression Reagent (Applied Biosystems). After denaturing at $95^{\circ} \mathrm{C}$ for 5 min, the samples were injected into an ABI 310 Genetic Analyzer (Applied Biosystems) and analyzed with ABI sequence analysis software, version 3.3 (Applied Biosystems). The location of the Tn 5 inserts was determined by comparing the sequence of regions flanking the element with the genome sequence of the citrus strain of $X$. fastidiosa (Simpson et al. 2000).

\section{Determination of the stability $X$. fastidiosa Tn5 mutants.}

Because $X$. fastidiosa cells tend to grow poorly when streaked from PD3 agar plates, the Tn5 mutants were first grown in liquid PD3 medium containing kanamycin and aliquots were plated on nonselective, solid PD3 plates. After incubating for 10 days, a small piece of agar containing visible colonies was transferred to nonselective, liquid PD3 medium. After incubating for 8 days, $10 \mu \mathrm{l}$ of the cell suspension were plated on PD3 medium supplemented with kanamycin and $10 \mu \mathrm{l}$ were plated on nonselective PD3 agar plates.

\section{ACKNOWLEDGMENTS}

This work was supported by the American Vineyard Foundation and the Viticulture Consortium Grants Program of the USDA-ARS. We gratefully acknowledge receiving Tn5 or Tn10 suicide vectors from D. Dahlbeck, B. Staskawicz, C. Pujol, and S. Lindow of the University of California-Berkeley and P. Sharma and P. Ronald of the University of California-Davis. We thank V. Stewart for his helpful advice and critical review of the manuscript.

\section{LITERATURE CITED}

Alexeyev, M. F., and Shokolenko, I. N. 1995. Mini-Tn10 transposon derivatives for insertion mutagenesis and gene delivery into the chromosome of Gram-negative bacteria. Gene 160:59-62.

Berg, D. E., and Berg, C. M. 1983. The prokaryotic transposable element Tn5. BioTechnology 1:417-435.

Bruijn, F. J., and Lupski, J. R. 1984. The use of transposon Tn5 mutagenesis in the rapid generation of correlated physical and genetical maps of DNA segments cloned into multicopy plasmids-A review. Gene 27:131-149.

Church, G. M., and Gilbert, W. 1984. Genomic sequencing. Proc. Natl. Acad. Sci. USA 91:1991-1995.

Davis, M. J., Purcell, A. H., and Thomson, S. V. 1978. Pierce's disease of grapevines: Isolation of the causal bacterium. Science 199:75-77.

Davis, M. J., French, W. J., and Schaad, N. W. 1981. Axenic culture of the bacteria associated with phony peach disease of peach and plum leaf scald. Curr. Microbiol. 6:309-314.

De Lima, J. E. O., Miranda, V. S., Hartung, J. S., Brlansky, R. H., Coutinho, A., Roberto, S. R., and Carlos, E. F. 1998. Coffee leaf scorch bacterium: Axenic culture, pathogenicity, and comparison with Xylella fastidiosa of citrus. Plant Dis. 82:94-97.

Feinberg, A. P., and Vogelstein, B. 1983. A technique for radiolabeling DNA restriction endonuclease fragments to high specific activity. Anal. Biochem. 132:6-13.

Frazier, N. W. 1965. Xylem viruses and their insect vectors. Pages 91-99 in: Procedures of the International Conference on Virus Vector on Perennial Hosts, with Special Reference to Vitis. W. B. Hewwitt, ed. University of California-Davis, Davis, CA, U.S.A.

Gehring, A. M., Nodwell, J. R., Beverley, S. M., and Losick, R. 2000. Genomewide insertional mutagenesis in Streptomyces coelicolor reveals additional genes involved in morphological differentiation. Microbiology 97:9642-9647.

Goheen, A. C., Nyland, G., and Lowe, S. K. 1973. Association of a Rickettsialike organism with Pierce's disease of grapevines and alfalfa dwarf and heat therapy of the disease in grapevines. Phytopathology 63:341-345.

Goryshin, I. Y., and Reznikoff, W. S. 1998. Tn5 in vitro transposition. J. Biol. Chem. 273:7367-7374.

Goryshin, I. Y., Miller, J. A., Kil, Y. V., Lanzov, V. A., and Reznikoff, W. S. 1998. Tn5/IS50 target recognition. Genetics 18:10716-10721.

Goryshin, I. Y., Jendrisak, J. J., Hoffman, L. M., Meis, R. M., and Reznikoff, W. S. 2000. Insertional transposon mutagenesis by electroporation of released Tn5 transposition complexes. Nat. Biotechnol. 18:97-100.

Hendson, M., Purcell, A. H., Deqiao, C., Smart, C., Guilhabert, M., and Kirkpatrick, B. 2001. Genetic diversity of Pierce's disease strains and other pathotypes of Xylella fastidiosa. Appl. Environ. Microbiol. 67:895-903.

Hopkins, D. L., and Mollenhauer, H. H. 1973. Rickettsia-like bacterium associated with Pierce's disease of grapes. Science 179:298-300.

Maniatis, T., Fritz, E. F., and Sambrook, J. 1984. Molecular Cloning: A Laboratory Manual. Cold Spring Harbor Laboratory, Cold Spring 
Harbor, N.Y., U.S.A.

Oka, A., Sugisaki, H., and Takanami, M. 1981. Nucleotide sequence of the kanamycin resistant transposon Tn903. J. Mol. Biol. 147:217-226.

Purcell, A. H. 1997. Xylella fastidiosa, a regional problem or global threat? J. Plant. Pathol. 79:99-105.

Simon, R., Priefer, U., and Pulher, A. 1983. A broad host range mobilization system for in vivo genetic engineering: transposon mutagenesis in Gram-negative bacteria. Biotechnology 784-791.

Simon, R., Quandt J., and Klipp, W. 1988. New derivatives of transposon
$\operatorname{Tn} 5$ suitable for mobilization of replicons, generation of operon fusions and induction of genes in Gram-negative bacteria. Gene 80:161-169.

Simpson, A. J. G., et al. 2000. The genome sequence of the plant pathogen Xylella fastidiosa. Nature 406:151-159.

Voelker, L. L., and Dybvig, K. 1998. Transposon mutagenesis. Methods Mol. Biol. 104:235-238.

Wilson, K. 1987. Preparation of genomic DNA from bacteria. Pages 2.4.1-2.4.2 in: Current Protocols in Molecular Biology. John Wiley \& Sons, New York 